\title{
A REVIEW OF GEOID MODELS OVER THE BRITISH ISLES: PROGRESS AND PROPOSALS
}

\author{
W E Featherstone \\ Curtin University of Technology, Western Australia
}

J G Olliver

University of Oxford, England

\begin{abstract}
The history of published geoid determination for the British Isles over the last fifty years is reviewed. This includes global geopotential models, tailored geopotential models, British gravimetric geoid models, and European gravimetric geoid models that cover the British Isles. Proposals are made for a collaborative venture to produce a new geoid model using the most recent data and computational techniques.
\end{abstract}

\section{INTRODUCTION}

The separation between the geoid and the ellipsoid, or the geoid height $(N)$, is required for many geodetic and land surveying applications, the most notable of which is the transformation between Global Positioning System (GPS)-derived ellipsoidal heights and orthometric heights. The geoid can be broadly defined as the equipotential surface of the Earth's gravity field that corresponds most closely with mean sea level (MSL) in the open oceans, ignoring oceanographic effects. For a description of the subtleties in the definition of the geoid, see [18] and [27]. The geoid forms the reference surface for orthometric heights and can, in practice, be realised as the local vertical datum through geodetic levelling from tide-gauge measurements of MSL.

On the mainland of Great Britain (ie. England, Wales and Scotland, which from here onwards, will be referred to simply as the British mainland), the vertical datum is the Ordnance Datum Newlyn (ODN), which was realised through MSL measurements made between 1915 and 1921 at the Newlyn tide gauge in Cornwall. In Northern Ireland, MSL Belfast provides the reference point of the vertical datum and was measured at the Clarendon Dock between 1951 and 1956. In the Republic of Ireland, the Irish Ordnance Datum is based on MSL measured at Portmoor Pier, Malin Head, County Donegal, between 1958 and circa 1970.

When establishing these local vertical datums, orthometric corrections have been applied to the spirit levelling measurements using surface gravity measurements. However, such orthometric corrections provide Helmert orthometric heights, which are only an approximation of true orthometric heights. Ideally, the integral mean value of gravity along the plumbline between the Earth's surface and the geoid should be used 
to convert levelled height differences to height differences based on the equipotential surfaces of the Earth's gravity field [35]. For the Helmert orthometric correction, the Poincaré-Prey reduction if the surface gravity measurements is used to approximate the integral mean value of gravity along the plumbline. This reduction assumes a constant bulk density of the topography, thus yielding Helmert orthometric heights, which are not necessarily based on the equipotential geoid.

In addition to the type of height system used, tidal and sea-surface topography effects on global scales (eg. geostrophic currents) and local scales (eg. the outflow of fresh water from rivers) cause tide-gauge measurements of MSL to depart from the equipotential geoid depending upon the location of the tide gauge. Also, since the MSL measurements used to establish the vertical datums in the British Isles were observed over different time epochs, the effect of the 18.6-year lunar tide is inconsistent among them. An arguably more controversial discrepancy (eg. the correspondence in numbers 257 and 260 of this Journal) is the apparent north-south slope between MSL measurements at tide gauges and geodetic levelling [78, 15].

Given the above considerations and the Ordnance Survey of Great Britain's (OSGB) intent not to re-define the ODN [5], the three vertical datums used in the British Isles are inconsistent with one another and, to the best of the authors' knowledge, no attempt has been made to rigorously unify them. This raises the question as to the appropriateness of a single geoid model for the transformation between GPS ellipsoidal and Helmert orthometric heights on the local vertical datums used over the entire British Isles. This will be discussed later in the paper.

Geoid models of the British Isles, or parts thereof, have been determined over the last fifty years with respect to the both the Airy 1830 and Geodetic Reference System 1980 (GRS80) ellipsoids using a variety of approaches. The geoid-Airy-ellipsoid separation is required, for example, to reduce geodetic survey data to the various national horizontal datums, since the neglect of $6.35 \mathrm{~m}$ of geoid-ellipsoid separation introduces horizontal scale errors of $1 \mathrm{ppm}$. However, it appears that this rigorous reduction to the ellipsoid is ignored for geodetic surveys conducted by the OSGB [44]. More recently, the proliferation of the use of GPS has driven the computation of geoids based on the GRS80 ellipsoid, which, for all practical purposes, is identical to the World Geodetic System 1984 (WGS84) ellipsoid.

This paper reviews the published history of the many geometric and gravimetric determinations of the geoid (or similar) that cover the British Isles, or parts thereof. Given the arguments about the inconsistencies in and among vertical datums and improvements in geoid determination theory and computation, proposals will be made to produce a new geoid model that is consistent with the vertical datums (new or old) used in the British Isles. This proposal is aligned with the approaches that have been adopted or are being considered elsewhere in the world. Although reference is made to the different height systems and vertical datums, this paper does not review the relative merits of each. Nevertheless, any new geoid model must be compatible with the existing or any newly defined height system used for the vertical datum. 


\section{ASTROGEODETICALLY DETERMINED GEOID MODELS}

The first determination of the geoid of the British mainland commenced in 1950, which was an astrogeodetically derived geoid section from Kent to Sutherland [65]. It comprises 43 observed vertical deflections with reference to the OSGB36 horizontal datum. By 1975, a further 149 deflections had been added to create a network spanning the entire British mainland (Figure 4 in [56]). These data were subsequently used to establish the 1977 astrogeodetic geoid of Britain with reference to the OSGB70(SN) horizontal datum [7]. These astrogeodetic geoid determinations can be assumed to refer to the Airy 1830 ellipsoid since the horizontal coordinates comprising the geodetic datums have changed by only a few metres between adjustments of the OSGB triangulation. The 1977 astrogeodetic geoid model was used in subsequent OSGB77(SN) and OS(SN)80 adjustments [44]. Since these astrogeodetic geoid models of Britain refer to the Airy 1830 ellipsoid, which is non-geocentric by virtue of its fit to the geoid in this region, they are not suited to the direct transformation of GPS-derived heights.

The same deflections of the vertical were used to produce an astrogeodetic geoid of the British mainland based on the European Datum 1950 and 1924 International Ellipsoid [53]. Olliver [56] transformed the OSGB70(SN) horizontal coordinates of these astrogeodetic stations to a geocentric datum to yield an astrogeodetically derived geoid with respect to the WGS84 ellipsoid. However, the 192 vertical deflections that were used cannot represent the short wavelength undulations in the geoid, and are subject to other errors (eg. [7]). Therefore, this astrogeodetic geoid model, though with respect to the WGS84 ellipsoid, cannot be used to accurately transform GPSderived ellipsoidal heights in all regions of the British mainland. Moreover, the homogeneous and dense spatial coverage offered by a gravimetric geoid (described later) makes this the preferable choice for vertical coordinate transformations.

\section{GEOID MODELS DERIVED FROM GPS AND LEVELLING}

Subtracting orthometric heights from GPS-derived WGS84 ellipsoidal heights at points yields discrete estimates of the separation between the local vertical datum and the WGS84 ellipsoid at these points, which can be interpolated to form a geometrically derived 'geoid-type' model. The term 'geoid-type' is used here because this approach strictly gives the separation between the local vertical datum and the WGS84 ellipsoid, rather than the separation between the geoid and WGS84 ellipsoid.

In the late 1980s, OSGB made relative carrier-phase GPS observations as part of its national GPS network [44] in conjunction with the European Reference Frame (EUREF) campaign. These provide WGS84 ellipsoidal heights at 54 points that cover most of the British mainland (Figure 1 in [56]). Subtracting ODN Helmert orthometric heights at the same stations allows discrete 'geoid-type' heights to be estimated with respect to the WGS84 ellipsoid. Importantly, this does not necessarily yield the equipotential geoid because of the considerations summarised in the Introduction, but it does provide a geoid-type surface that allows a more direct transformation of GPSderived ellipsoidal heights to Helmert orthometric heights on the ODN. 
There are several limitations to using this geoid-type model to transform heights. The first is that many of the stations occupied with GPS by the OSGB are co-located with existing hill-top stations of the OSGB triangulation. These usually only have trigonometrically determined heights, which are less accurate than those points with spirit levelled heights. This is because the primary aim of the National GPS network was to relate the OSGB horizontal datums to EUREF [44]. There is also some question as to the quality of these GPS data because they were observed using mostly single-frequency GPS instruments over long $(>100 \mathrm{~km})$ baselines and the data processing algorithms used are less sophisticated than those currently employed. Also, precise GPS satellite ephemerides were not available from the International GPS Service (IGS) at the time this GPS network was observed.

Olliver [56] used these 54 GPS and ODN heights to geometrically derive a geoidtype surface of the British mainland with respect to the WGS84 ellipsoid. The International Terrestrial Reference Frame (ITRF) coordinates at the Herstmonceux satellite laser ranging station provided absolute control on this geoid-type model. A subsequent least-squares network adjustment [56] estimated the standard errors in the GPS-derived ellipsoidal heights to be $4 \mathrm{~cm}$. The standard error of the ODN heights is estimated to be between $3 \mathrm{~cm}$ and $30 \mathrm{~cm}$ [56]. As for the astrogeodetic geoid models, the 54 GPS-derived geoid-type heights available in 1991 cannot define the shortwavelength components. Therefore, it is also insufficient to use this geoid-type model to transform GPS-derived ellipsoidal heights to the ODN in all regions of the British mainland.

Since 1991, OSGB has observed a passive GPS network comprising approximately 1000 stations at a $20-30 \mathrm{~km}$ spacing over the entire British mainland. However, these data are not publicly available with which to compute a geoid-type model with a higher spatial resolution than Olliver's [56] model. Alternatively, GPS surveyors can establish their own geometrical geoid models over the area in which they are working simply by occupying benchmarks that surround the survey area. Previous papers published in this Journal $[\mathbf{2 3}, \mathbf{6}]$ describe this technique in more detail.

\section{Global GeOPOTENTIAL Models}

A variety of global geopotential models, which express the Earth's gravity field and thus geoid heights in terms of spherical harmonic basis functions, have been computed by various groups around the world which, obviously, cover the British Isles. There are essentially two classes of global geopotential model: satellite-only and combination. The satellite-only global geopotential models are derived from the analysis of the perturbations in the orbits of artificial Earth satellites (eg. [63]). Terrestrial gravity and terrain data, as well as satellite altimeter data over the oceans, can be included in the solution to produce the combined global geopotential models. The combined global geopotential models are often of a higher spatial resolution than the satellite-only global geopotential models, and are thus usually better suited to the transformation of GPS-derived heights. 
Table 1. Satellite-only and combined global geopotential models published since 1990

\begin{tabular}{|l|c|l|l|}
\hline \multicolumn{1}{|c|}{ model } & degree & \multicolumn{1}{c|}{ type } & \multicolumn{1}{c|}{ citation } \\
\hline GEM-T2 & $36^{*}$ & combined & {$[\mathbf{4 6}]$} \\
\hline GEM-T2S & $36^{*}$ & satellite-only & {$[\mathbf{4 6}]$} \\
\hline GEM-T3 & 50 & combined & {$[\mathbf{4 3}]$} \\
\hline GEM-T3S & 50 & satellite-only & {$[\mathbf{4 3}]$} \\
\hline JGM-1 & 70 & combined & {$[\mathbf{5 1 ,}, \mathbf{5 2}]$} \\
\hline JGM-1S & 60 & satellite-only & {$[\mathbf{5 1}, \mathbf{5 2}]$} \\
\hline JGM-2 & 70 & combined & {$[\mathbf{5 1 , 5 2}]$} \\
\hline JGM-2S & 60 & satellite-only & {$[\mathbf{5 1}, \mathbf{5 2}]$} \\
\hline JGM-3 & 70 & combined & {$[\mathbf{7 6}]$} \\
\hline PGTF-4 & 50 & satellite-only & {$[\mathbf{7 0}]$} \\
\hline PGTF-4A & 50 & combined & {$[\mathbf{7 0}]$} \\
\hline TEG-2 & 54 & combined & {$[\mathbf{7 5}]$} \\
\hline TEG-2B & 54 & combined & {$[\mathbf{7 5}]$} \\
\hline TEG-3 & 70 & combined & {$[\mathbf{7 7}]$} \\
\hline GRIM4-S1 & 50 & satellite-only & {$[\mathbf{6 6}]$} \\
\hline GRIM4-C1 & 50 & combined & {$[\mathbf{6 6 , 6 4}]$} \\
\hline GRIM4-S2 & 50 & satellite-only & {$[\mathbf{6 7}]$} \\
\hline GRIM4-C2 & 50 & combined & {$[\mathbf{6 7}, \mathbf{6 4}]$} \\
\hline GRIM4-S3 & 50 & satellite-only & {$[\mathbf{6 8}]$} \\
\hline GRIM4-C3 & 60 & combined & {$[\mathbf{6 8}]$} \\
\hline GRIM4-S4 & $60 *$ & satellite-only & {$[\mathbf{6 9}]$} \\
\hline GRIM4-C4 & 72 & combined & {$[\mathbf{6 9}]$} \\
\hline GRIM5-S1 & 120 & satellite-only & {$[\mathbf{2}]$} \\
\hline GRIM5-C1 & 120 & combined & {$[\mathbf{3 3}]$} \\
\hline OSU89A & 360 & combined & {$[\mathbf{6 1}]$} \\
\hline OSU89B & 360 & combined & {$[\mathbf{6 1}]$} \\
\hline OSU91A & 360 & combined & {$[\mathbf{6 2}]$} \\
\hline OGE12 & 360 & combined & {$[\mathbf{2 8}]$} \\
\hline GFZ93A & 360 & combined & {$[\mathbf{2 9}]$} \\
\hline GFZ93B & 360 & combined & {$[\mathbf{2 9}]$} \\
\hline GFZ95A & 360 & combined & {$[\mathbf{3 0 ]}$} \\
\hline GFZ96 & 359 & combined & {$[\mathbf{3 1}]$} \\
\hline GFZ97 & 359 & combined & {$[\mathbf{3 2}]$} \\
\hline EGM96S & 70 & satellite-only & {$[\mathbf{4 2 ]}$} \\
\hline EGM96 & 360 & combined & {$[\mathbf{4 2 ]}$} \\
\hline GAO-98 & 360 & combined & {$[\mathbf{8}]$} \\
\hline
\end{tabular}

* includes some additional (usually resonant) coefficients above this degree. 
Table 1 lists the global geopotential models that have been published since 1990, together with the maximum spherical harmonic degree and order, whether they are satellite-only or combined solutions, and a citation. The spatial resolution (half of the minimum wavelength) of the global geopotential model (in kilometres) can be deduced simply by dividing $19980 \mathrm{~km}$ by the maximum degree, whilst remembering to include the cosine effect for meridian convergence towards the poles.

Given the spherical harmonic coefficients of a global geopotential model, the GPS surveyor can compute geoid heights at any position. This can be achieved using the variant of Rapp's FORTRAN77 computer software [57], which is available free-ofcharge from the US National Imagery and Mapping Agency's (NIMA) web-site (http://164.214.2.59/GandG/wgs-84/egm96.html). Most of the global geopotential model coefficients in Table 1 can be downloaded free-of-charge from the International Geoid Service (http://ipmtf14.topo.polimi.it/ iges/db/model.html) or from the late Prof H-G. Wenzel's web-site (http://www.gik.uni-karlsruhe.de/ wenzel/geopmods.htm).

It appears to be acknowledged internationally that the best of the current global geopotential models is EGM96 [42], whose coefficients can be downloaded free-ofcharge from NIMA's web-site (http://164.214.2.59/GandG/wgs-84/egm96.html). Alternatively, EGM96 geoid heights can be computed on-line at the same web-site.

An additional consideration in the use of global geopotential models for transforming GPS-derived ellipsoidal heights to orthometric heights is that the models usually yield the quasigeoid [58]. The difference between the geoid and quasigeoid essentially relates to the height systems that are based upon them (eg. chapter 4 in [35]). Orthometric heights are based on the geoid, whereas normal heights are based on the quasigeoid. The difference between the geoid and quasigeoid comes primarily from the treatment of the Earth's topography in the geodetic boundary-value problem. The difference between the geoid and quasigeoid, and thus between normal and orthometric heights, is approximately proportional to the square of the elevation of the topography. This difference may reach 10-20 centimetres over the British Isles (deduced from [35]). Accordingly, a quasigeoid-to-geoid term should be included if using a global geopotential model in the British Isles. The quasigeoid-to-geoid coefficients are available with the EGM96 model (http://164.214.2.59/GandG/wgs84/egm96.html).

Lambeck and Coleman [41] give a review of global geopotential modelling from 1958 to 1982. Nerem et al. [50] and Rapp [59] extend and update this review, and also outline the future prospects for global gravity field modelling. Lambeck and Coleman make an important point: "...the various models are not as good as they are said to be. If they were, the differences between them should not be so great as they are...". In the authors' opinion, this statement is still largely true today (cf. [50]). Accordingly, any GPS surveyor that uses a global geopotential model, or any other geoid model, to transform heights must always perform their own accuracy evaluations in each survey area to determine the most suitable model.

Current degree-360 global geopotential models (Table 1) can only provide a spatial resolution of the geoid of approximately $19880 / 360=55.5 \mathrm{~km}$. This resolution is usually insufficient for localised GPS surveys. Therefore, tailored geopotential models 
or regional gravimetric geoid models (described sequentially next) can improve upon the spatial resolution and generally the precision of global geopotential models. If available, these should generally be used in preference to the global geopotential models for GPS applications.

\section{TAILORED GEOPOTENTIAL MODELS}

Global geopotential models can usually be refined by a process named tailoring, where the existing spherical harmonic coefficients are adjusted, and often extended to higher degrees, using gravity and terrain data that may not necessarily have been used in the global geopotential model [40]. Tailored geopotential models can be developed either globally or over a particular region. However, the regional tailored geopotential models only apply over the area in which the tailoring was applied, because spurious effects can occur in areas where no data are available (eg. [84]). The tailored spherical harmonic coefficients can be used with the same computer software used to compute geoid heights from a global geopotential model (described earlier). However, some minor modifications to this software are necessary to account for higher degree and order spherical harmonic expansions.

The IFE88E2 regionally tailored geopotential model [1] is based on the OSU86F global geopotential model, and has been tailored using only European gravity data. The tailoring was applied over a region bound by $30^{\circ} \mathrm{N} \leq \phi \leq 73^{\circ} \mathrm{N}$ and $30^{\circ} \mathrm{W} \leq \lambda \leq$ $46^{\circ} \mathrm{E}$, with an additional gravity data rectangle that covers Scandinavia $\left(73^{\circ} \mathrm{N} \leq \phi \leq\right.$ $81.5^{\circ} \mathrm{E}$ and $3^{\circ} \mathrm{E} \leq \lambda \leq 36^{\circ} \mathrm{E}$ ). The maximum spherical harmonic degree of this model is 360 , which is the same as the global geopotential model upon which it is based. As such, the IFE88E2 model can only be expected to improve the precision of OSU86F in these parts of Europe, and cannot improve its $\sim 55 \mathrm{~km}$ spatial resolution. A total of 6,715 mean free-air gravity anomalies, referred to the GRS80 ellipsoid, in $0.5^{\circ}$ by $0.5^{\circ}$ compartments were used for the tailoring. These data were sourced from the Institut für Erdmessung, University of Hannover, Germany, and Kort-og Matrikelstyrelsen, Denmark. Given the vintage of the gravity data used in IFE88E2, it is believed that the EGM96 global geopotential model is probably superior.

The GPM3E97A, GPM3E97B and GPM3E97C regionally tailored geopotential models for Europe [83] also now supersede the IFE88E2 model. The respective maximum spherical harmonic degree and order of these models is 1800,1080 and 720 , which equate to spatial resolutions of approximately $11 \mathrm{~km}, 18.5 \mathrm{~km}$ and $28 \mathrm{~km}$, respectively. A variant of the usual tailoring process was used: instead of using gravity data, quasigeoid heights from the EGG97 European gravimetric quasigeoid model ([14] described later) were used to tailor the EGM96 global geopotential model. This tailoring was applied over a region bound by $25^{\circ} \mathrm{N} \leq \phi \leq 77^{\circ} \mathrm{N}$ and $35^{\circ} \mathrm{W} \leq \lambda \leq$ $67.4^{\circ} \mathrm{E}$. The EGG97 quasigeoid heights were taken from a 5 , by 5 , grid for GPM3E97A, a 10' by 10' grid for GPM3E97B and a 15' by 15' grid for GPM3E97. For reasons of data confidentiality, these models are not yet available in the public domain. However, since GPM3E97A, GPM3E97B and GPM3E97C are derived from the EGG97 European gravimetric quasigeoid model, it is possibly more convenient for the GPS-surveyor to simply use the higher resolution EGG97 model in preference. 
The GPM98A, GPM98B and GPM98C globally tailored geopotential models have been computed to spherical harmonic degree 1800 by Wenzel [84]. The spatial resolution of this model is approximately $11 \mathrm{~km}$. It is debatable whether the GPM98 models should be classified as combined global geopotential models (described earlier) or globally tailored geopotential models. This is because the GPM98 models are based on the degree-20 expansion of EGM96 and global 5' by 5' grids of gravity anomalies have been used to iteratively compute the higher degree spherical harmonic coefficients. However, in areas where no local gravity data were available to Wenzel, such as Australia, the GPM98 models provide results that are worse than the degree360 expansion of EGM96 (Wenzel, 1998, pers. comm.). In areas where gravity data were available, the GPM98 models generally outperformed EGM96 in comparisons with GPS and spirit levelling data on the local vertical datum [84].

Only the spherical harmonic coefficients to degree 720 of the GPM98 models are available in the public domain, which can be downloaded, together with a computer program to compute grids of geoid heights, from http://www.gik.unikarlsruhe.de/ wenzel/geopmods.htm. Given the fit of the GPM98 and EGM96 models to GPS and levelling data in Germany [84], it can be inferred that the GPM98 models will outperform EGM96 in the British Isles. This is because additional gravity data have been included in this region. However, as no reliable GPS and spirit levelling data in the British Isles are available to the authors (described earlier), this inference cannot be verified here. Again, the GPS surveyor should perform his/her own evaluations of these geoid models in the areas in which they will be used to transform GPS-derived ellipsoidal heights.

Table 2 summarises the regionally and globally tailored geopotential models that cover the British Isles.

Table 2. Tailored geopotential models that cover the British Isles

\begin{tabular}{|l|c|l|l|}
\hline \multicolumn{1}{|c|}{ model } & degree & coverage & citation \\
\hline IFE88E2 & 360 & Europe & {$[\mathbf{1}]$} \\
\hline GPM3E97A & 720 & Europe & {$[\mathbf{8 3}]$} \\
\hline GPM3E97B & 1080 & Europe & {$[\mathbf{8 3}]$} \\
\hline GPM3E97C & 1800 & Europe & {$[\mathbf{8 3}]$} \\
\hline GPM98A, B, C & 1800 & global & {$[\mathbf{8 4}]$} \\
\hline
\end{tabular}

\section{GRAVIMETRICALLY REFINED REGIONAL GEOID MODELS}

In areas with a dense, homogeneous and complete coverage of gravity and terrain data, which is also available to geodesists, the gravimetric method of combining a global geopotential model with Stokes's formula, or a modification thereof, provides probably the best means of computing the geoid with respect to a geocentric ellipsoid. Modern regional gravimetric geoid computations use a global geopotential model to furnish the long and intermediate wavelengths of the geoid. The shorter wavelength geoid components are added, and the medium wavelengths can be supplemented, using 
terrestrial gravity and terrain data through some numerical implementation of Stokes's formula, or a modification thereof. The various approaches to gravimetric geoid determination, and arguments in favour or against each approach, will not be reviewed here. Instead, only the arguments pertinent to the computation of gravimetric geoid models that cover the British Isles will be presented.

Olliver $[\mathbf{5 3}, \mathbf{5 4}]$ made the first gravimetric determination of the geoid of the British Isles. This model, herein termed OX79, used quadrature-based numerical integration for a direct application of the spherical Stokes formula including the then-available free-air gravity anomalies over the whole Earth, which was a challenge given the computational power available at that time. No global geopotential model or terrain data were used in the computations. Accordingly, OX79 is termed a free-air co-geoid because gravimetric terrain corrections and indirect effects were neglected. The OX79 regional gravimetric co-geoid model refers to the GR67 ellipsoid and is given on a 10' by $20^{\prime}$ (approximately $18 \mathrm{~km}$ ) grid bound by $50^{\circ} \mathrm{N} \leq \phi \leq 60^{\circ} \mathrm{N}$ and $10^{\circ} \mathrm{W} \leq \lambda \leq 2^{\circ} \mathrm{E}$. The standard error of OX79 was estimated internally to be approximately $1 \mathrm{~m}$ [54]. Given the vintage of the gravity data, ellipsoid used, estimated precision and spatial resolution, OX79 is not suited to the best currently available transformation of GPSderived ellipsoidal heights.

The early- to mid-1980s saw a hiatus in gravimetric geoid computations for the British Isles by British investigators and institutions. However, the increased demand for precise geoid undulations for the transformation of GPS-derived heights triggered the renewed in interest in geoid determination, both nationally and internationally. In the mid-1980s, three separately conceived $\mathrm{PhD}$ projects began to investigate the gravimetric computation of the geoid of the British Isles or smaller regions thereof. These were:

1. The University of Nottingham [16, 26], under contract to the OS, were to compute a gravimetric geoid model of the British mainland with the specific aim of enabling GPS to be used in place of spirit levelling [3], but this model has not been used by the OS [5] (discussed later).

2. The University of Edinburgh [72, 73, 37] computed a gravimetric geoid model of the British mainland for use in the UK Tide Gauge Project [17] and compared the planar fast Fourier transform (P-FFT) technique with quadrature-based numerical implementation of a modified Stokes's integral.

3. The University of Oxford $[\mathbf{1 9}, \mathbf{2 1}, \mathbf{2 2}]$ computed a gravimetric geoid model of the British Isles, controlled in part by GPS and levelling data, to investigate the theoretical and quadrature-based numerical procedures, and to assess the application of the geoid in geophysical interpretation of the Earth's structure.

The investigators involved in each of these three projects chose, for their own reasons, to approach the numerical computations differently. This point alone has raised some question as to which, if any, of these models is the most suitable for the transformation of GPS-derived heights to the local vertical datums used in the British Isles. This question will probably remain unanswered until they can be compared with GPS and spirit levelling data on the local vertical datums and when using the same global geopotential model, gravity and terrain data. Theoretically, however, whichever 
numerical implementation of Stokes's integral is used should produce the same geoid model from the same input data.

Since these three geoid studies, two other gravimetric geoid models have been computed for part of the British Isles and western North Sea at the University of Edinburgh [38]. Also, several European regional geoid and quasigeoid models, which cover the British Isles, have been computed mainly at the University of Hannover, Germany. The following Sections will review the geoid models produced by the University of Nottingham (1990), University of Edinburgh (1990-1995), University of Oxford (1992) and University of Hannover (1982-1997). This will also include a brief explanation of the OSGM91 geoid model, which has recently (1999) been released by OSGB as the 'official' geoid model of Great Britain.

\section{The 1990 Nottingham Gravimetric Geoid Model}

The 1990 Nottingham gravimetric geoid model [16, 26], herein termed NOT90, used least-squares collocation (LSC) to compute a gravimetric geoid model covering only the British mainland. NOT90 was computed on a $0.03^{\circ}$ by $0.03^{\circ}$ grid in 20 rectangular blocks that are bounded approximately by $49^{\circ} \mathrm{N} \leq \phi \leq 61^{\circ} \mathrm{N}$ and $8^{\circ} \mathrm{W} \leq \lambda \leq$ $2^{\circ} \mathrm{E}$ (Figure 6.5 of [26]). Not all of these blocks abut these bounds, but abut one another and cover only land areas.

The degree-360 expansion of the OSU86E global geopotential model [60] was used in NOT90 via the remove-compute-restore procedure. The gravity data used were taken from the British Geological Survey's (BGS) database. However, the BGS gravity data were filtered from their approximate spatial density of one observation per square-kilometre on land to a $2.5^{\prime}$ 'by $4^{\prime}$ grid by taking the nearest gravity observation to this graticule. This resulted in 12,606 points on land and 19,000 points at sea [26]. The GRS67 ellipsoid was used for the gravity anomalies (as supplied by the BGS), whereas the GRS80 ellipsoid was used for OSU86E. Accordingly, there is a disparity in the normal gravity reference systems used in the NOT90 geoid model.

A $1 \mathrm{~km}$ by $1 \mathrm{~km}$ digital elevation model (DEM) of mean elevations was supplied by the BGS over three rectangular blocks covering Wales and the south-west, northern England and Scotland (Figure 5.4 in [26]). The residual terrain modelling (RTM) technique [24] was used to compute gravimetric terrain corrections in these areas. Due to the resolution of this DEM, near-zone terrain corrections will be omitted. No gravimetric terrain corrections were applied in other areas and no primary or secondary indirect effects were computed anywhere. Therefore, this solution can be classified as a mixture of a terrain-corrected, free-air co-geoid and a free-air co-geoid. Gerrard [26] internally estimated the precision of the NOT90 geoid model to be $\pm 5 \mathrm{~cm}$, falling to $\pm 7 \mathrm{~cm}$ in mountainous regions.

A well-vaunted virtue of LSC is that it has the ability to use heterogeneous data types and provides error estimates of the geoid heights. However, additional gravity field information, such as deflections of the vertical and GPS-levelling data, although available, was not included in the NOT90 geoid solution. For each LSC geoid computation point, a matrix of dimensions equal to the number of data points must be inverted, which requires a large amount of computer memory. Even after filtering the 
BGS gravity data to a $2.5^{\prime}$ by 4' grid, computer limitations at the University of Nottingham at the time dictated that NOT90 had to be computed in 20 rectangular blocks.

As could be expected, this approach caused some discontinuities in the geoid model at the boundaries of each block (p.137-139 of [26]). To remove these discrepancies, geoid heights at the edge of each block were sequentially fixed to make the geoid heights between blocks consistent, starting in south-east England. Gerrard [26] admits that "...the geoid surface is being warped by the introduction of fixed geoid heights, leading to a strange systematic effect across the country." In addition to this fundamental problem, it appears as though this approach has not been effective, because discrepancies remain in the NOT90 geoid model. For instance, OSGB sources reported $70 \mathrm{~cm}$ offsets in some regions. To illustrate these discrepancies, a profile of the NOT90 geoid model at $55^{\circ} \mathrm{N}$ has been compared with some other geoid models in Figure 1. The discontinuities in the NOT90 geoid model, which is expected to be a smooth surface, are visible at approximately $3^{\circ} \mathrm{W}$ and $1.5^{\circ} \mathrm{W}$.

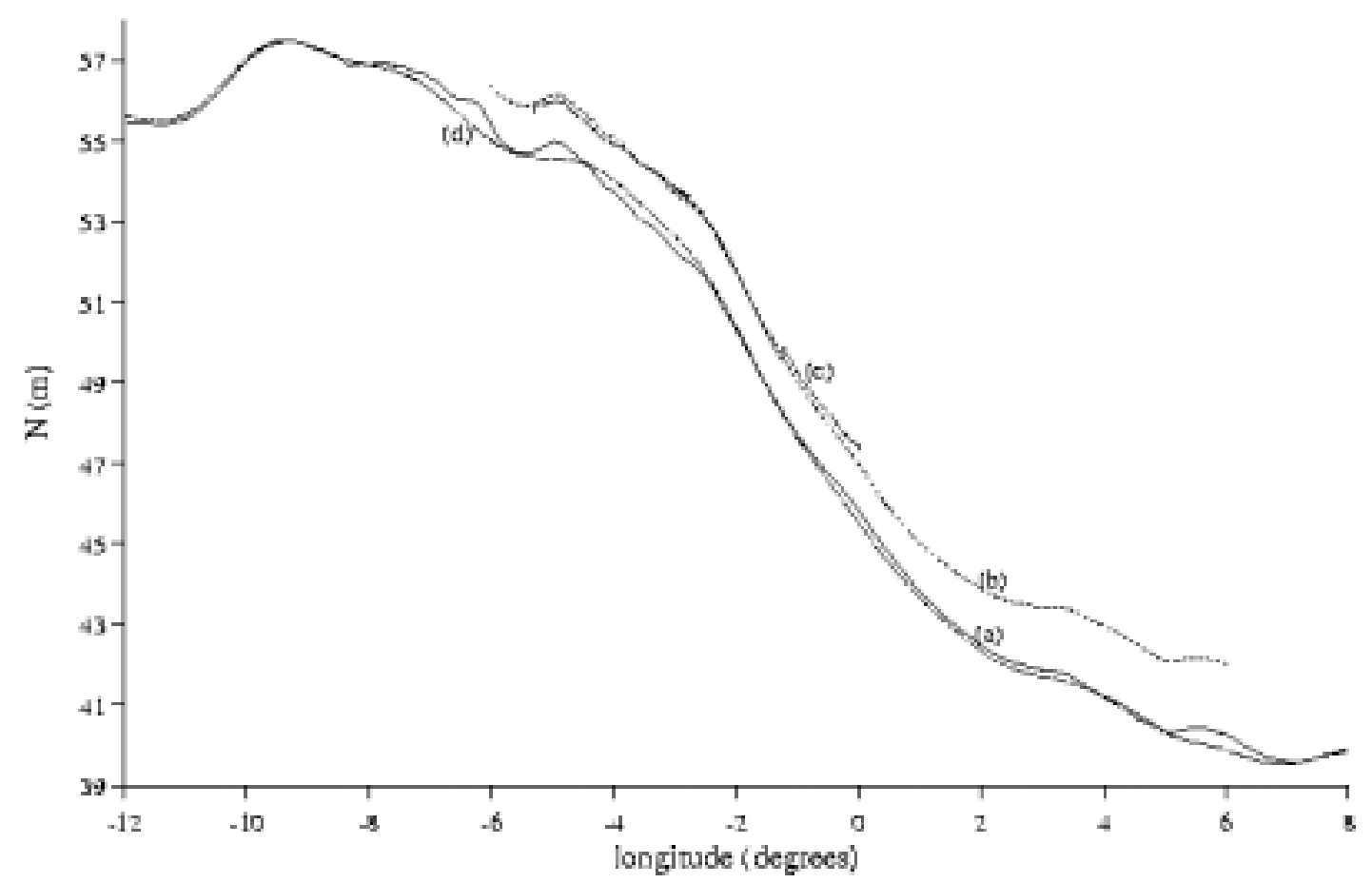

Figure 1. A profile of the 1990 Nottingham geoid solution at $55^{\circ} \mathrm{N}$ (dot-dashed line, c) showing discontinuities at approximately $3^{\circ} \mathrm{W}$ and $1.5^{\circ} \mathrm{W}$ in relation to (solid line, a) the 1992 Oxford geoid solution, (dashed line, b) the 1990 Edinburgh geoid solution and (dot-dashed line, d) the OUS91A global geopotential model (heights in metres above the GRS80 ellipsoid). [The approximate 1m offset between the geoid solutions is due to inclusion of a zero-degree term in the computation of the Oxford and OSU91A geoid models. None of these geoid models take into account the departure between MSL and the geoid due to global or local sea-surface topography effects. The Irish coastline crosses $55^{\circ} \mathrm{N}$ at approximately $8.5^{\circ} \mathrm{W}$ and $6^{\circ} \mathrm{W}$. The British coastline crosses $55^{\circ} \mathrm{N}$ at approximately $5.25^{\circ} \mathrm{W}$ and $\left.1.5^{\circ} \mathrm{W}.\right]$

The OSGB and Nottingham University observed GPS networks specifically to provide geometric control on the NOT90 geoid model. They were designed to coincide with second-order levelling lines of the ODN in regions of varying terrain. 
These were the topographically benign East Anglia, the Midlands and Pennines, and mountainous North Wales (Figure 9.4 in [26]). Comparisons between a selection of the GPS-levelling and NOT90 geoid heights exhibit centimetre-level agreement over shorter baselines within each LSC block [26]. However, this agreement is not expected between blocks due to the discontinuities described earlier and shown in Figure 1. The NOT90 geoid model is not currently available to the authors in order to determine the full extent and magnitude of these discontinuities.

Significantly, the NOT90 geoid model has not been adopted by the OSGB for its future GPS-levelling campaigns [5], despite being the subject of an OSGB contract. This will be referred to again in a later section on the OSGM91 national geoid model.

\section{The 1990-95 Edinburgh Gravimetric Geoid Models}

The 1990 Edinburgh geoid study [72, 73] compared the planar fast Fourier transform (P-FFT) implementation of an unmodified Stokes's integral with quadraturebased numerical integration of a Meissl-modified [48] Stokes's integral. The P-FFT computation was shown to be computationally faster than numerical integration by approximately four orders of magnitude [73]. The P-FFT implementation used a planar approximation of Stokes's kernel, which, at that time, was necessary to convert Stokes's formula to a convolution integral. Since 1990, refinements to the FFT implementation of Stokes's integral have been published [34] which do not require such kernel simplification. However, in order to reduce the error introduced by the planar approximation, the British National Grid (BNG) map projection has been used in all of the Edinburgh geoid computations [37].

Hipkin [36] gives the theoretical basis of the Edinburgh geoid calculations, where Bouguer gravity anomalies on land are used in Stokes's integral and the contribution of the terrain to the geoid is calculated separately. The EDIN89 geoid model uses this in conjunction with a remove-compute-restore approach based upon the degree-360 expansion of the OSU86E global geopotential model [60]. The land and marine gravity data used were taken from the Edinburgh University database (Figure 3.2 in [73]) and gravity anomalies were recomputed on the GRS80 ellipsoid. However, these gravity data were filtered onto an approximate $2 \mathrm{~km}$ by $2 \mathrm{~km}$ grid on land and $4 \mathrm{~km}$ by $4 \mathrm{~km}$ and $10 \mathrm{~km}$ by $10 \mathrm{~km}$ grids at sea, depending on the spatial density of the gravity observations. Bouguer gravity anomalies on land and free-air gravity anomalies at sea were interpolated onto a $2 \mathrm{~km}$ by $2 \mathrm{~km}$ BNG grid using a two-dimensional version of the Gregory-Newton cubic interpolation formula over the area bound by BNG $0 \mathrm{~km} \leq$ $\mathrm{N} \leq 998 \mathrm{~km}$ and $\mathrm{BNG} 100 \mathrm{~km} \leq \mathrm{E} \leq 998 \mathrm{~km}$.

The DEM used in the computation of the EDIN89 geoid model was constructed from three sources. The first was a $1 \mathrm{~km}$ by $1 \mathrm{~km}$ DEM of mean elevations supplied by the BGS, which only covers the more mountainous regions of the British mainland (Figure 3.4 in [73]). The second was a $0.5 \mathrm{~km}$ by $0.5 \mathrm{~km}$ DEM of mean elevations between BNG $550 \mathrm{~km}$ and BNG $710 \mathrm{~km}$, constructed at the University of Edinburgh [36]. In the remaining areas of the British mainland, a DEM of mean elevations was constructed using the heights supplied with the gravity observations on land. The three DEMs were combined onto the same $2 \mathrm{~km}$ by $2 \mathrm{~km}$ BNG grid used for the gravity data 
grid. The contribution of the terrain to the geoid in Hipkin's method [37] was computed using a planar FFT algorithm and a constant topographic density of $2,670 \mathrm{kgm}^{-3}$. Gravimetric terrain corrections were taken from the BGS gravity database, which are computed wherever they are significant and include innermost zones estimated in the field. No indirect effects were computed according to Hipkin's definition of the geoid [37]. Therefore, the Edinburgh geoid models can be classified as terrain-corrected, free-air co-geoids.

Due to computer memory limitations at the University of Edinburgh at that time, the EDIN89 geoid model was computed in four overlapping squares of $700 \mathrm{~km}$ by $700 \mathrm{~km}$ in dimension. These four geoid solutions showed both mean and long-wavelength discrepancies along their common boundaries (Figures 6.4 and 6.5 in [73]). Therefore, they were merged together using an inverse distance weighting function that extends $400 \mathrm{~km}$ from the edge of each overlapping square [73]. The final geoid solution, EDIN89, is referred to the GRS80 ellipsoid and stored on a $2 \mathrm{~km}$ by $2 \mathrm{~km}$ BNG grid that extends approximately from $8^{\circ} \mathrm{W}$ to $8^{\circ} \mathrm{E}$ and from $50^{\circ} \mathrm{N}$ to $58^{\circ} \mathrm{N}$. Internal estimates of the error in EDIN98 are $\pm 2 \mathrm{~cm} / 100 \mathrm{~km}[73,37$, and comparisons with the Nottingham GPS-levelling data (described earlier) are $\pm 5 \mathrm{~cm} / 100 \mathrm{~km}[73]$.

Hipkin [38] describes the computation of two additional geoid models at the University of Edinburgh, called EDIN891 and EDIN91. These geoid models have the same $2 \mathrm{~km}$ by $2 \mathrm{~km}$ grid-size and spatial coverage as EDIN89. Hipkin also reported [38] preparation of a new geoid model, called EDIN95, though this has not yet been published.

The EDIN891 geoid model was computed simply by subtracting the degree-360 geoid expansion of the OSU86E global geopotential model [60] from EDIN89, then adding the degree-360 geoid expansion of the OSU91A global geopotential model [62]. It is argued that this is theoretically incorrect because it violates the removecompute-restore approach. Specifically, the OSU91A-implied gravity anomalies must also be removed from the gravity data before a residual geoid computation is performed with respect to OSU91A. Only these residual geoid undulations can be used, otherwise spurious long-wavelength errors will result from the use of different global geopotential models. It is incorrect to simply add a residual gravimetric geoid based on one global geopotential model to another global geopotential model.

The EDIN91 geoid model [38] uses the same gravity and terrain data used for EDIN89 [73] and is based on the degree-360 expansion of the OSU91A global geopotential model. In this case, a proper application of the remove-compute-restore approach was used. The computational approach used for the residual geoid was based on the P-FFT approximation of Stokes's formula with the BNG map projection carried out as a single operation on the whole gravity dataset and, as with EDIN89, used the theory of Hipkin [36]. Therefore, this geoid model is also classified as a terraincorrected free-air co-geoid because indirect effects were omitted.

\section{The 1992 Oxford Gravimetric Geoid Model}

The 1992 Oxford gravimetric geoid model [19, 21, 22] used quadrature-based numerical integration of a Meissl-modified Stokes's formula [48] over a spherical cap 
of 1.95-degrees radius about each computation point and the OSU91A global geopotential model [62]. This approach was chosen for the following reasons. Firstly, the LSC implementation of Stokes's formula is limited in that it involves a matrix of dimensions equal to the number of observations (mentioned earlier). At the time this study commenced (1988), the P-FFT implementation of Stokes's formula was not conclusively established as an optimal procedure, but appeared to be applied simply because of speed rather than accuracy considerations. Furthermore, the planar implementation required that the kernel be approximated away from its true form.

The quadrature-based numerical implementation of Stokes's formula, although computationally much slower than the FFT, allowed some of the original problems inherent to Stokes's formula to be addressed. Kernel modifications were also applied to reduce the truncation error as the integration was limited to a spherical cap of 1.95 degrees radius, which was chosen empirically from comparisons with 54 GPS-ODN data (see earlier Section on GPS-levelling-derived geoids). This cap size consideration is not explicitly considered in the FFT implementation (the whole gravity data rectangle is used) and included implicitly by the correlation length of the covariance function in LSC. Comparisons of gravimetric and geometrical geoid heights were also used to test various kernel modifications, and the Meissl [48] modification was chosen.

The 1992 Oxford geoid, herein termed OX92, is based on the degree-257 expansion of the OSU91A global geopotential model. This truncation was chosen at the point beyond which the global error degree variances exceeded the global degree variances of OSU91A. The gravity data used were supplied by the BGS on land and at sea, and additional data from the North Sea, Northern Ireland and the Republic of Ireland were also included (Figure 1 of [22]). The BGS marine gravity data were provided in confidence from four grids that were derived from a combination of BGS and oil company gravity data. Therefore, some of these data have not been used in any other geoid models that cover the British Isles. The 326,154 gravity data were recomputed on the GRS80 ellipsoid, then arithmetically averaged onto a 2' by 4' grid bound by $48^{\circ} \mathrm{N} \leq \phi \leq 63^{\circ} \mathrm{N}$ and $12^{\circ} \mathrm{W} \leq \lambda \leq 7^{\circ} \mathrm{E}$, which is the same area over which the OX92 geoid model was computed.

A 2' by 4' DEM of mean topographic elevations over the entire British Isles was derived from a variety of sources, including the BGS, the University of London and the elevations of the gravity stations in areas where the other models did not extend. Because of this relatively coarse grid spacing, the high-frequency terrain corrections and indirect effects are omitted from the OX92 geoid solution. The terrain data were used according to their expected reliability, in the order of London University, BGS and gravity station elevations. Gravimetric terrain corrections were computed on a 2' by 4' grid using the first term of Moritz's formula [49] and primary indirect effects were computed using the first two terms of Wichiencharoen's formula [85]. As such, OX92 is classified as a 'geoid', as opposed to a co-geoid.

Pessimistic internal estimates give an absolute accuracy of $\pm 8 \mathrm{~cm}$, which may reduce to $\pm 1 \mathrm{~cm}$ over $100 \mathrm{~km}$ [22]. Comparisons of OX92 with GEOSAT satellite altimeter data in the western North Sea indicate its precision as $\pm 3 \mathrm{~cm}$ in the $20-700 \mathrm{~km}$ range 
[74]. However, this error estimate will probably increase on land due to topographic effects.

\section{The 1999 OSGM91 National Geoid Model}

In 1999, OSGB released a national geoid model covering the British mainland, called OSGM91 (http://www.ordsvy.gov.uk/service/gps-co/geo3.htm). The claimed accuracy of OSGM91 is $10 \mathrm{~cm}$ (95\% confidence), but the derivation of this value is unknown and no substantiation of it is given by OSGB. Also, OSGB does not document the computation and origin of this geoid model. For instance, there is no information on the global geopotential model, gravity and terrain data or computational techniques used. Discussions with concerned people from universities and OSGB, as well as a conference poster presentation [47], allow the following inferences to be made. However, these must be treated with some caution until OSGB releases an 'official' description of the OSGM91 geoid model.

The OS contracted the 1990 Nottingham geoid (described earlier). However, the discontinuities between the 20 LSC computation blocks remaining in the NOT90 geoid model caused the OS to recontract Nottingham University to address these problems. No satisfactory remedy was found and, instead, Nottingham University purchased the EDIN89 model from the University of Edinburgh, which was then supplied to the OS [47]. As stated, this is a terrain-corrected, free-air co-geoid because the indirect effects have been omitted, according to Hipkin's definition of the geoid [36]. Stewart [73] estimates the difference between the equipotential geoid and this co-geoid to be 10$20 \mathrm{~cm}$ in mountainous regions of the British mainland. Therefore, it is argued that if OSGM91 is simply a 'rebadged' EDIN89, it is not strictly suited to the transformation of GPS-derived ellipsoidal heights to the vertical datums on the British mainland, which use Helmert orthometric heights.

However, from the conference poster presentation [47], it appears as though the EDIN89 gravimetric model has been tilted to fit the OSGB's archive of GPS ellipsoidal heights and ODN Helmert orthometric heights over the British mainland. Some mention was made of using higher order polynomial fits [47], but it is not clear whether this, a tilt, or no surface fitting has been applied to EDIN89 to produce OSGM91. This 'warping' of a gravimetric geoid model to fit the GPS and levelling data is preferable for the transformation of GPS-derived heights to the local vertical datum, because it makes the transformation direct by accounting for the deficiencies in the datum and geoid model. However, it does not satisfy the needs of other users of geoid models, such as oceanographers who wish to derive ocean currents and quasistationary sea-surface topography from satellite altimetry. The 'warping' of geoid models will be discussed later in the section on Proposals and Prospects.

\section{The 1982-1997 European Gravimetric Geoid Models}

Since 1980, the Institut für Erdmessung (IfE) at the University of Hannover, Germany, has been involved in the production of European gravimetric geoid and quasigeoid models (eg. [79]). By definition, the quasigeoid and geoid do not coincide 
on land, and their difference is approximately proportional to the square of the topographic elevation. The quasigeoid is used for the transformation of normal heights, which are used in many countries in eastern Europe. As Helmert orthometric heights are employed in the British Isles (described earlier), a geoid model that is consistent with this height system is better suited to the transformation of heights in this part of the world.

The first European gravimetric geoid model is called EGG1 [80, 81]. It is based upon the degree-20 expansion of the GEM9 global geopotential model, and includes terrestrial gravity data on GRS80 (Figure 2.5 of [80]), but no topographic data. As such, it is classified as a free-air co-geoid. The EGG1 co-geoid was computed on a 12' by $20^{\prime}$ (approximately $20 \mathrm{~km}$ ) grid in the region bound by $30^{\circ} \mathrm{N} \leq \phi \leq 73^{\circ} \mathrm{N}$ and $30^{\circ} \mathrm{W}$ $\leq \lambda \leq 46^{\circ} \mathrm{E}$ using a stochastically modified Stokes formula, which takes into account error models of the gravity data and global geopotential model. The internal estimate of the absolute precision of EGG1 is $\pm 0.9 \mathrm{~m}$ and $0.3-1.1 \mathrm{~m}$ over distances from 100$1000 \mathrm{~km}[\mathbf{7 9}, \mathbf{8 0}]$. Given the vintage of the gravity data and that EGG1 is a co-geoid, it is not suited to the transformation of GPS-derived heights in the British Isles. Moreover, there are large gaps in the gravity data coverage over the British Isles (Figure 2.5 of $[\mathbf{8 0}]$ ), which will introduce medium- and long-wavelength errors in and around this region.

The EGG1 free-air co-geoid model was augmented using approximately 5000 deflections of the vertical to generate the European astrogravimetric geoid, called EAGG1 [4]. The inclusion of deflections of the vertical improved upon the accuracy of EGG1 in regions where there were sparse or no terrestrial gravity data [79]. The EAGG1 model is of the same spatial resolution and covers the same geographic area as EGG1. No error estimates for this model have been published, but it is reasonable to assume that it is slightly more precise than EGG1, especially in those areas devoid of gravity data. Again, due to the vintage of this model and that it is predominantly a free-air co-geoid, it is not suited to the transformation of GPS-derived heights in the British Isles.

In 1990, the International Association of Geodesy (IAG) chose the IfE as the computing centre for a series of new European gravimetric geoid and quasigeoid models. The progress of this project has been regularly reported in the geodetic literature, mainly via conference proceedings (eg. [10] and [12]). Three quasigeoid and two geoid solutions for Europe have been released since 1995, called EGG95 [13], EGG96 [14] and EGG97 [11]. Each of these solutions is based on a high-degree global geopotential model, terrestrial gravity and terrain data and used a stochastically modified Stokes's kernel. Molodensky correction terms for the quasigeoid have been neglected, which may only cause $\sim 1 \mathrm{~cm}$ error in the British Isles [11]. The residual geoid computations have been performed using the one-dimensional FFT (1D-FFT) algorithm [34], which does not suffer from the approximations used in earlier planar and spherical FFT implementations.

The EGG95 quasigeoid model [13] uses approximately 2.3 million gravity anomalies and approximately 700 million topographic elevations over Europe. A 100200m-resolution DEM of mean elevations was used over the United Kingdom, but no 
regional DEM was available for the Republic of Ireland (Figure 2 in [13]). Instead, the mean elevations contained within the ETOPO5 DEM were used in this region. The gravity and terrain data were transformed, as best as then possible, to common reference systems and validated through comparisons with values interpolated from nearby data. In areas with a limited marine gravity data coverage, notably to the west of the British Isles (Figure 1 in [13]), satellite-altimeter-derived gravity anomalies were used. The EGG95 quasigeoid heights were computed on a 1' by 1.5' grid bound by $25^{\circ} \mathrm{N} \leq \phi \leq 77^{\circ} \mathrm{N}$ and $35^{\circ} \mathrm{W} \leq \lambda \leq 67.4^{\circ} \mathrm{E}$ using the 1D-FFT technique. The degree360 expansion of the OSU91A global geopotential model [62] was used in the removecompute-restore technique. Terrain effects were computed using numerical integration of the residual terrain modelling (RTM) technique [24] with a $15^{\prime}$ by $15^{\prime}$ moving average elevation filter. Based on GPS and spirit levelling data, estimates of relative accuracy of EGG95 are $1-5 \mathrm{~cm}$ over $10-100 \mathrm{~km}$ and $5-20 \mathrm{~cm}$ over a few $1000 \mathrm{kms}$, which agree with internal error estimates [13]. However, these GPS-derived estimates include a bias and tilt fit to the residuals, which absorb differences between the GPS, levelling and quasigeoid data, thus making the external error estimates overly optimistic.

The EGG96 quasigeoid and geoid models [14] use largely the same data and exactly the same computational techniques as EGG95. The data differences are in the use of the degree-70 expansion of the JGM-3 global geopotential model [76], the degree-71 to -360 expansion of the OSU91A global geopotential model [62], and supplementary marine gravity anomalies derived from ERS-1 satellite altimetry. No new gravity or terrain data appear to have been included for the British Isles (Figures 1 and 2 in [14]). The computed EGG96 quasigeoid model was converted to a geoid model using mean Bouguer gravity anomalies (eg. chapter 8 in [35]). A - $0.5 \mathrm{~m}$ zerodegree term was also applied. The error estimates of EGM96 are the same as EGG95, though no comparison between the models was given in [14]. However, the longwavelength components of EGG96 are expected to be improved due to the use of the JGM-3 global geopotential model.

The EGG97 quasigeoid and geoid models $[\mathbf{1 1}, \mathbf{7 9}]$ were computed using the same numerical techniques as EGG95 and EGG96. The EGG97 models include new gravity and low-resolution terrain data from Russia, and are based on the degree-360 expansion of the EGM96 global geopotential model [42]. A $-0.5 \mathrm{~m}$ zero-degree bias term was applied to the models. A correction to the tide-free system [18] was also applied in accordance with IAG recommendations. As with EGG96, EGG97 geoid heights were computed from the computed EGG97 quasigeoid heights using mean Bouguer gravity anomalies. The EGG97 geoid and quasigeoid heights were computed on a $1^{\prime}$ by $1.5^{\prime}$ grid bound by $25^{\circ} \mathrm{N} \leq \phi \leq 77^{\circ} \mathrm{N}$ and $35^{\circ} \mathrm{W} \leq \lambda \leq 67.4^{\circ} \mathrm{E}$. Internal and external error estimates of the accuracy of EGG97 agree and are $1-5 \mathrm{~cm}$ over $10-100 \mathrm{~km}$ and $5-20 \mathrm{~cm}$ over few $1000 \mathrm{kms}$. Again, these external error estimates include a bias and tilt fit to the residuals between the GPS, levelling and EGG97 data. The EGG97 gravimetric geoid and quasigeoid models are available for scientific uses on CD-ROM, which is available from the IAG for a contribution of US\$100 to the IAG fund (http://www.gfy.ku.dk/ iag/egg97.html). 
Table 3 gives a summary of the various gravimetric geoid, quasigeoid and co-geoid models that cover the British Isles, or parts thereof. It is recommended that only the models that are more compatible with Helmert orthometric heights, such as OX92 or EGG96 and EGG97 geoid models, are used for the transformation of GPS-derived ellipsoidal heights to the vertical datums used over the British Isles. The use of cogeoid or quasigeoid models may result in discrepancies of up to approximately $20 \mathrm{~cm}$ in the more mountainous regions. However, the 'geoid' models are subject to their own approximation errors. For example, the use of mean elevations from a DEM to compute topographic corrections to the geoid omits the high-frequency, near-zone effects. Similarly, long-wavelength errors due to data gaps and a limited integration area will be different among the Oxford, Edinburgh and European models [82]. Indeed, it is unlikely that any single one of the models reviewed above provides the best transformation of GPS-derived heights to the vertical datums used over the British Isles. Since, the accuracy of any geoid, co-geoid or quasi-geoid model is a function of position, each model may be better suited to this purpose in different areas. As stated, GPS surveyors must always perform their own accuracy evaluations in each survey area to determine the most suitable model. 
Table 3. Summary of gravimetric geoid, co-geoid and quasigeoid models which cover all or part of the British Isles.

\begin{tabular}{|c|c|c|c|c|c|c|}
\hline model & type & technique & geopotential model & extent & resolution & citation \\
\hline OX79 & co-geoid & $\mathrm{NI}$ & none; global Stokes & $50-60^{\circ} \mathrm{N}, 10 \mathrm{~W}-2^{\circ} \mathrm{E}$ & $10^{\prime} \times 20^{\prime}$ & {$[53,54]$} \\
\hline NOT90 & co-geoid & LSC & OSU86E & $\sim 49-61^{\circ} \mathrm{N}, \sim 8 \mathrm{~W}-2^{\circ} \mathrm{E}$ & $0.03^{\circ} \times 0.03^{\circ}$ & {$[16,26]$} \\
\hline EDIN89 & co-geoid & P-FFT & OSU86E & $\sim 49.5-60^{\circ} \mathrm{N}, \sim 7.5 \mathrm{~W}-6^{\circ} \mathrm{E}$ & $2 \mathrm{~km} \times 2 \mathrm{~km}$ & {$[72,73,37]$} \\
\hline EDIN891 & co-geoid & P-FFT & OSU86E/OSU91A & $\sim 49.5-60^{\circ} \mathrm{N}, \sim 7.5 \mathrm{~W}-6^{\circ} \mathrm{E}$ & $2 \mathrm{~km} \times 2 \mathrm{~km}$ & {$[38]$} \\
\hline EDIN91 & co-geoid & P-FFT & OSU91A & $\sim 49.5-60^{\circ} \mathrm{N}, \sim 7.5 \mathrm{~W}-6^{\circ} \mathrm{E}$ & $2 \mathrm{~km} \times 2 \mathrm{~km}$ & {$[38]$} \\
\hline OSGM91 & unknown & P-FFT \& fit & OSU86E & unknown & unknown & {$[47]$} \\
\hline OX92 & geoid & NI & OSU91A & $48-63^{\circ} \mathrm{N}, 12 \mathrm{~W}-8^{\circ} \mathrm{E}$ & $2^{\prime} \times 4^{\prime}$ & {$[19,21,22]$} \\
\hline EGG1 & co-geoid & NI & GEM9 & $30-73^{\circ} \mathrm{N}, 30 \mathrm{~W}-46^{\circ} \mathrm{E}$ & $12^{\prime} \times 20^{\prime}$ & {$[80]$} \\
\hline EAGG1 & unclassified & NI \& astro & EGM96 & $30-73^{\circ} \mathrm{N}, 30 \mathrm{~W}-46^{\circ} \mathrm{E}$ & $12^{\prime}$ x 20' & [4] \\
\hline EGG95 & quasigeoid & 1D-FFT & OSU91A & $25-77^{\circ} \mathrm{N}, 35 \mathrm{~W}-67.4^{\circ} \mathrm{E}$ & $1^{\prime} \times 1.5$ ' & [13] \\
\hline EGG96 & geoid & 1D-FFT & OSU91A/JGM-3 & $25-77^{\circ} \mathrm{N}, 35 \mathrm{~W}-67.4^{\circ} \mathrm{E}$ & $1^{\prime} \times 1.5$ ' & [14] \\
\hline EGG96 & quasigeoid & 1D-FFT & OSU91A/JGM-3 & $25-77^{\circ} \mathrm{N}, 35 \mathrm{~W}-67.4^{\circ} \mathrm{E}$ & $1^{\prime} \times 1.5$ ' & [14] \\
\hline EGG97 & geoid & 1D-FFT & EGM96 & $25-77^{\circ} \mathrm{N}, 35 \mathrm{~W}-67.4^{\circ} \mathrm{E}$ & $1^{\prime} \times 1.5^{\prime}$ & {$[\mathbf{1 1}]$} \\
\hline EGG97 & quasigeoid & 1D-FFT & EGM96 & $25-77^{\circ} \mathrm{N}, 35 \mathrm{~W}-67.4^{\circ} \mathrm{E}$ & $1^{\prime} \times 1.5^{\prime}$ & {$[11]$} \\
\hline
\end{tabular}

$\mathrm{NI}=$ quadrature numerical integration, $\mathrm{P}-\mathrm{FFT}=$ planar fast Fourier transform,

1D-FFT = one-dimensional fast Fourier transform, astro = astrogeodetic geoid modelling, fit $=$ fit to GPS and levelling data 


\section{PROPOSALS AND PROSPECTS}

Recall that the primary application of a geoid model in land surveying is for the transformation of GPS-derived ellipsoidal heights to elevations on the local vertical datum. Obviously, using different geoid-type models (ie. gravimetric 'geoid', cogeoid or quasigeoid) and height systems in the local vertical datum (ie. Helmert orthometric, orthometric or normal heights) will produce different results. Arguably the most important requirement is for consistency between the height system and geoid-type model. Based on this review, the most pressing requirement is a comparison of all the geoid-type models listed in Tables 1, 2 and 3 with co-located GPS and Helmert orthometric height data over the entire British Isles. This will ascertain which of the currently available models is the most appropriate for the transformation of heights and in which areas of the British Isles this holds. As stated, it is likely that no single model will produce the best results over the entire British Isles.

Such an evaluation of the geoid-type models for the use of a GPS land surveyor is not presently possible because of the restrictions on access to GPS-derived ellipsoidal heights over the British Isles. The 54 geometrical geoid-type heights compiled by Olliver [56] are not suited to this task because of their spatial coverage, the vintage of the GPS data and the quality of the levelling data at some of these stations. Moreover, several of the geoid-type models listed in Tables 1,2 and 3 are not available in the public domain. Therefore, a cooperative effort is required among those who have computed geoid-type models that cover the British Isles and the Ordnance Surveys of Great Britain, Northern Ireland and Ireland. Only this type of collaborative venture will quantify which model(s) is(are) best suited to support the activities of GPS land surveyors in the British Isles.

Acknowledging the limited amount of information available to the authors concerning the OSGM91 geoid-type model of the British mainland, it appears that it is not based on the latest computational theories and techniques and does not use all the gravity and terrain data available. This is considered a highly undesirable scenario because there are several other geoid-type models available, which use more gravity and terrain data and are based on arguably better computational techniques. It is interesting to note that a 100-200m DEM of the British mainland and Northern Ireland was used for the EGG97 models, while it has not been made available to British investigators. Given these arguments, it is recommended that one of the more recent models, or even a mosaic of the existing models that takes into account the expected benefits of each, is adopted for the transformation of GPS heights to the local vertical datums in the British Isles. A far more preferable approach would be a collaborative venture among the three Ordnance Surveys, the relevant geological surveys and interested Universities to compute a new gravimetric geoid model of the entire British Isles.

It is suggested that such a collaborative venture should include: (1) access to all land and marine gravity observations, particularly those so far restricted, such as to the west of Ireland; (2) access to the latest and high-resolution digital elevation models; (3) access to all the GPS-levelling and astrogeodetic levelling data previously mentioned; 
(4) testing and possible inclusion of satellite-altimeter-derived sea-surface heights and gravity anomalies; (5) testing and possible inclusion of satellite gravity gradiometry data, when available; (6) consideration and modelling of global and local sea-surface topography; (7) the correct implementation of Stokes's integral, including improved corrections for the topography and downward continuation, ellipsoidal corrections, and optimised integration kernels. It is also argued that a single model should be used for the transformation of all GPS-derived ellipsoidal heights in each country. This makes data management simpler and avoids degradation of the respective geodetic data infrastructures. The use of a single model can easily be encouraged through free access to the model and interpolation software. This has been applied very successfully in Australia, where the AUSGeoid98 model, Windows-based software, and an on-line (bi-cubic) interpolation facility are available at http://www.auslig.gov.au/geodesy/ausgeoid/geoid.htm.

As an interim solution for the direct transformation of GPS-derived ellipsoidal heights to the vertical datums used in the British Isles, the gravimetric geoid-type model could be augmented with GPS and levelling data. This is aligned with the approach being used or considered in other countries, such as the USA [71], France [39], Germany [9], Canada [25] and Australia [20]. This 'warping' of a gravimetric geoid model to fit the GPS and levelling data may be preferable for the transformation of GPS-derived heights to the local vertical datum because it makes the transformation direct by accounting for the differences among vertical datum realisations described in the Introduction. However, it does not support the other users of geoid models, such as geophysicists and oceanographers. Moreover, it clouds some of the issues surrounding geoid determination and practical vertical datum definition. These include unresolved systematic errors in geodetic levelling for the ODN [78], the use of different vertical datums in the British Isles, and the departure of MSL from the equipotential geoid due to sea-surface topography.

From the practical point of view for the land surveyor, a model of the separation between the local vertical datum and the WGS84 ellipsoid is the most desirable [20]. This can be achieved immediately by warping the geoid-type models as mentioned above. This is simple in that it gives a single value that is applied to the GPS-derived ellipsoidal height to give an elevation on the local vertical datum. However, this approach is subject to error because it will absorb any errors in the vertical datum and the GPS data used to create the warped surface. Also, such a model is inappropriate for purposes other than vertical coordinate transformations. Therefore, it is important not to confuse such a warped surface with the 'true' geoid. Another problem is that it would make elevations on the distinctly different vertical datums used in the British Isles appear to have the same elevation, whereas in reality they may differ by over one metre.

In any re-computation of the geoid of the British Isles to support the activities of the GPS land surveyor, the question of the local vertical datums must be considered concurrently, especially if Helmert orthometric (or other) heights are to be used as the benchmark by which the model is assessed. It is now widely acknowledged that the ODN contains a cumulative north-south error that amounts to approximately half a 
metre. Therefore, warping any geoid model to fit these data, whilst providing a very satisfactory interim solution, is very unsatisfactory in the longer term. Therefore, as part of the future geoid modelling process, the vertical datum definition should be included as an integral part, as should the effects of sea-surface topography. Given the increasing number of co-located GPS and geodetically levelled heights, the geoid model could conceivably be used in the redefinition of the local vertical datums. It is even possible to derive correction surfaces for the three vertical datums to model out the systematic errors, which will avoid costly geodetic levelling of the British Isles (cf. [5]) yet provide improved vertical datums.

As well as considering the redefinition of the local vertical datums, and taking the warping issue one stage further, an analogue of the approach being used in the United States could be applied to the British Isles. The US National Geodetic Survey produces two geoid-type models: one is a scientific solution and the other is a warped model to support the direct transformation of GPS heights to the North American vertical datums [71]. In the case of the British Isles, the following geoid models and 'correction' surfaces could be produced:

- a pure gravimetric geoid model (a scientific solution);

- models of the separation between existing vertical datums and WGS84 ellipsoid;

- models of the separation between any new vertical datums and WGS84 ellipsoid;

- correction surfaces between the old and new vertical datums; and

- sea-surface topography models.

This would keep the various issues separate and avoid the undesirable scenario where users of height information in the British Isles are misled into thinking that there are no problems with the local vertical datums.

From a scientific point of view, the future for geoid determination of the British Isles is relatively bright. The availability of what is possibly the densest coverage of gravimetric and geodetic data and a reasonable range of terrain make it a useful 'field laboratory' in which to test geoid computation theories and procedures. The planned satellite gravity gradiometry missions will also improve the long-wavelength geoid. However, in order for these studies to proceed effectively, all the necessary data must be provided to the investigators. The return is obvious: an improved geoid model to support the activities of land surveyors that use GPS in the British Isles, as well as for others such as oceanographers and geophysicists.

\section{ACKNOWLEDGEMENTS}

We would like to thank Curtin University of Technology for funding the travel of Dr Olliver to Australia to co-author this review and collaborate in several other geodetic studies. We would also like to thank the reviewers, particularly Dr Roger Hipkin, for their constructive comments on this manuscript.

\section{References}

1. Basic, T., Denker, H., Knudsen, P., Sondheim, D. and Torge, W. 1989. A new geopotential model tailored to gravity data in Europe. In Gravity, Gradiometry and Gravimetry (eds Rummel, R. and Hipkin, R.G.), Springer, Berlin, 109-118. 
2. Biancale, R., Balmino, G., Lemoine, J.-M., Marty, J.-C., Moynot, B., Barlier, F., Exertier, P., Laurain, O., Gegout, P., Schwintzer, P., Reigber, Ch., Bode, A., König, R., Massmann, F.-H., Raimondo, J.C., Schmidt, R., Zhu, S.Y., 2000. A new global Earth's gravity field model from satellite orbit perturbations: GRIM5-S1, Geophysical Research Letters, [27]: 3611-3615.

3. Bordley, R.F., Christie, R.R., Dodson, A.H. and Gerrard, S.M.E. 1989. Taking the spirit out of levelling. Land and Minerals Surveyor [7]: 526-534.

4. Brennecke, J., Lelgemann D., Reinhhart, E., Torge, W., Weber, G. and Wenzel, H-G. 1983. A European astro-gravimetric geoid, Reihe B. Nr. 269, German Geodetic Commission, Frankfurt/Main.

5. Christie, R.R., 1994. A new geodetic heighting strategy for Great Britain, Survey Review [32], 328343.

6. Collier, P. and Croft, M., 1997. Heights from GPS in an engineering environment. Survey Review, [264]: 76-86 and [265]: 11-18.

7. Dean, J.D.A., 1980. The astrogeodetic determination of the geoid in Great Britain, Professional Paper No 29, Ordnance Survey, Southampton, England, 47 pp.

8. Demianov, G., Maiorov, A. and Medvedev, P., 2000. Comparison and evaluation of the new Russian global geopotential model to degree 360, In Geodesy Beyond 2000: Challenges for the Next Decade (ed Schwarz, K.-P.), Springer, Berlin, 96-106.

9. Denker, H., 1998. Evaluation and improvement of the EGG97 quasigeoid model for Europe by GPS and levelling data. Proc. Second Continental Workshop on the Geoid in Europe (eds. Vermeer M and Adam, J.) Budapest, March, 53-61.

10. Denker, H. and Torge W. 1992. Recent developments of the European geoid project. Proc. First Continental Workshop on the Geoid in Europe (ed. Holota, P.), Prague, May, 31-39

11. Denker, H. and Torge, W. 1998. The European gravimetric quasigeoid EGG97 - An IAG-supported continental enterprise, In Geodesy on the Move: Gravity, Geoids, Geodynamics, and Antarctica (eds. Forsberg, R., Feissl, M. and Dietrich, R.), Springer, Berlin, 249-254.

12. Denker, H., Behrend, D. and Torge, W. 1995a. European gravimetric geoid: status report 1994. In Gravity and Geoid (eds Sünkel, H and Marson, I.), Springer, Berlin, 423-432.

13. Denker, H., Behrend, D. and Torge, W. 1995b. The European gravimetric quasigeoid EGG95. International Geoid Service Bulletin [4], 3-11.

14. Denker, H., Behrend, D. and Torge, W. 1997. European gravimetric quasigeoid EGG96. In Gravity, Geoid and Marine Geodesy (eds. Segawa, J., Fujimoto, H. and Okubo, S.), Springer, Berlin, 523539.

15. Dixon, J., 1979. Apparent sea level slopes - Ireland. Chartered Land Surveyor / Chartered Minerals Surveyor [1(1)], 46-50.

16. Dodson, A.H. and Gerrard, S.M.E. 1989. A relative geoid for the UK. In Sea Surface Topography and the Geoid (eds. Sünkel, H. and Baker, T.), Springer, Berlin, 47-52.

17. Dodson, A.H., Bingley, R.M. and Stewart, M.P. 1995. Using high-precision GPS to aid absolute geoid datum definition. In Gravity and Geoid (eds. Sünkel, H. and Marson, I.), Springer, Berlin, 511-518.

18. Eckman, M., 1998. What is the geoid? In Coordinate Systems, GPS, and the Geoid (ed. Vermeer, M.), Report 95:5 of the Finnish Geodetic Institute, Masala, 49-51.

19. Featherstone, W.E., 1992. A GPS controlled gravimetric determination of the geoid of the British Isles. D.Phil thesis, Oxford University. 272 pp.

20. Featherstone, W.E., 1998. Do we need a gravimetric geoid or a model of the base of the Australian Height Datum to transform GPS heights?, The Australian Surveyor [43(4)], 273-280.

21. Featherstone, W.E. and Olliver, J.G., 1993. The gravimetric geoid of the British Isles computed using a modified Stokes integral. In The European Geoid Determination, (eds. Forsberg R. and Denker, H.) Kort-og Matrikelstyrelsen, Copenhagen, 19-25.

22. Featherstone, W.E. and Olliver, J.G., 1994. A new gravimetric determination of the geoid of the British Isles, Survey Review [32], 464-478. 
23. Featherstone, W.E., Dentith, M.C. and Kirby, J.F., 1998. Strategies for the accurate determination of orthometric heights from GPS, Survey Review [34(267)], 278-296.

24. Forsberg, R., 1985. Gravity field terrain effect computations by FFT, Bulletin Geodesique [59], 342-360.

25. Fotopoulos, G., Kotsakis, C. and Sideris, M.G., 2000. A new Canadian geoid model in support of levelling by GPS, Geomatica [54(1)], 53-62

26. Gerrard, S.M.E. 1990. The geoid, GPS and levelling. PhD thesis, Nottingham University. 249 pp.

27. Grafarend, E.W., 1994. What is a geoid? In Geoid and its Geophysical Interpretations (eds. Vanicek, P. and Christou N.P.) CRC Press, Boca Raton, 3-32.

28. Gruber, T. and Bosch, W., 1992. OGE12, a new 360 gravity field model, In Geodesy and Physics of the Earth (eds. Montag, H. and Reigber, C.), Springer, Berlin, 83-86.

29. Gruber, T.H. and Anzenhofer, M. 1993. The GFZ 360 gravity field model. In The European Geoid Determination (eds. Forsberg R. and Denker, H.) Kort-og Matrikelstyrelsen, Copenhagen, 13-18.

30. Gruber, T., Anzenhofer, M. and Rentsche, M. 1996. The 1995 GFZ high-resolution gravity model. In Global Gravity Field and its Temporal Variations (eds. Rapp, R.H., Cazneve, A. and Nerem, R.S.), Springer, Berlin, 61-70.

31. Gruber, T. Anzenhofer, M, Rentcsh, M. and Schwintzer, P. 1997a. Improvements in high-resolution gravity field modelling at GFZ. In Gravity, Geoid and Marine Geodesy (eds. Segawa, J., Fujimoto, H. and Okubo, S.), Springer, Berlin, 445-452.

32. Gruber, T., Bode, A., Reigber, C. and Schwintzer, P., 1997b. DPAF global Earth models based on ERS, Proceedings of 3rd ERS Symposium, Florenz.

33. Gruber, T., Bode, A., Reigber, C., Schwintzer, P., Balmino, G., Biancale, R., Lemoine, J.-M., 2000. GRIM5-C1: Combination solution of the global gravity field to degree and order 120. Geophysical Research Letters, [27]: 4005-4009

34. Haagmans, R.H.N., de Min, E. and van Gelderen, M., 1993. Fast evaluation of convolution integrals on the sphere using 1D-FFT, and a comparison with existing methods for Stokes's integral. manuscripta geodaetica [18], 227-241.

35. Heiskanen, W.H. and Moritz, H., 1967. Physical Geodesy, Freeman, San Francisco, USA.

36. Hipkin, R.G. 1988. Bouguer anomalies and the geoid: a reassessment of Stokes's method. Geophysical Journal International [92], 53-66.

37. Hipkin, R.G. 1995. How close are we to a centimetric geoid? In Gravity and Geoid (eds. Sünkel, H. and Marson, I.), Springer, Berlin, 529-538.

38. Hipkin, R.G. 1996. Geoid models for Great Britain and the North Sea. International Geoid Service Bulletin [4], 131-135.

39. Jiang, Z. and Duquenne, H., 1996. On the combined adjustment of gravimetrically determined geoid and GPS levelling stations, Journal of Geodesy, [70], 505-514.

40. Kearsley, A.H.W. and Forsberg, R., 1990. Tailored geopotential models - applications and shortcomings, manuscripta geodaetica [15], 151-158.

41. Lambeck, K. and Coleman, R. 1983. The Earth's shape and gravity field: a report of progress from 1958 to 1982. Geophysical Journal of the Royal Astronomical Society [74], 25-54.

42. Lemoine, F.G., Kenyon, S.C., Factor, J.K., Trimmer, R.G., Pavlis, N.K., Chinn, D.S., Cox, C.M., Klosko, S.M., Luthcke, S.B., Torrence, M.H., Wang, Y.M., Williamson, R.G., Pavlis, E.C., Rapp, R.H. and Olson, T.R., 1998. The development of the joint NASA GSFC and the National Imagery and Mapping Agency (NIMA) geopotential model EGM96, NASA/TP-1998-206861, National Aeronautics and Space Administration, USA.

43. Lerch, F.J., Nerem, R.S., Putney, B.H., Felsentreger, T.L., Sanchez, B.V., Marshall, J.A., Klosko, S.M., Patel, G.B., Williamson, R.G., Chinn, D.S., Chan, J.C., Rachlin, K.E., Chandler, N.L., McCarthy, J.J., Luthcke, S.B., Pavlis, N.K., Pavlis, D.E., Robbins, J.W., Kapoor, S. and Pavlis, E.C., 1994. A geopotential model from satellite tracking, altimeter, and surface gravity data: GEMT3. Journal of Geophysical Research [99(B2)], 2815-2839. 
44. Macdonald, A.S. and Christie, R.R., 1991. From miles to millimetres: the story of geodesy at Ordnance Survey 1791-1991. Survey Review [31], 126-147.

45. Marsh, J.G., Lerch, F.J., Putney, B.H., Christodoulidis, D.C., Smith, D.E., Felsentreger, T.L., Sanchez, B.V., Klosko, S.M., Pavlis, E.C., Martin, T.V., Robbins, J.W., Williamson, R.G., Colombo, O.L., Rowlands, D.D., Eddy, W.F., Chandler, N.L., Rachlin, K.E., Patel, G.B., Bhati, S. and Chinn, D.S., 1988. A new gravitational model of the Earth from satellite tracking data: GEMT1. Journal of Geophysical Research [93(B6)], 6169-6215.

46. Marsh, J.G., Lerch, F.J., Putney, B.H., Felsentreger, T.L., Sanchez, B.V., Klosko, S.M., Patel, G.B., Robbins, J.W., Williamson, R.G., Engelis, T.L., Eddy, W.F., Chandler, N.L., Chinn, D.S., Kapoor, S., Rachlin, K.E., Braatz, L.E. and Pavlis, E.C., 1990. The GEM-T2 gravitational model. Journal of Geophysical Research [95(B13)], 22043-22071.

47. Mason, S.H., Wilson J.I. and Holland, D.A., 1997. Relating GPS positions with Great Britain's national mapping and height datums, Presented to the IAG Scientific Assembly, Rio de Janeiro.

48. Meissl, P., 1971. Preparations for the numerical evaluation of second-order Molodensky-type formulas, Report 163, Department of Geodetic Science and Surveying, Ohio State University.

49. Moritz, H., 1968. On the use of the terrain correction in solving Molodensky's problem, Report 108, Department of Geodetic Science and Surveying, Ohio State University, Columbus, USA.

50. Nerem, R.S., Jekeli, C. and Kaula, W.M. 1995. Gravity field determination and characteristics: retrospective and prospective. Journal of Geophysical Research [100], 15053-15074.

51. Nerem, R.S., Lerch, F.J., Williamson, R.G., Klosko, S.M., Robbins, J.W. and Patel, G.B., 1994a. Gravity model improvement using the DORIS tracking system on the SPOT2 satellite. Journal of Geophysical Research [99(B2)], 2791-2813.

52. Nerem, R.S., Lerch, F.J., Marshall, J.A., Pavlis, E.C., Putney, B.H., Tapley, B.D., Eanes, R.J., Ries, J.C., Schutz, B.E., Shum, C.K., Watkins, M.M., Klosko, S.M., Chan, J.C., Luthcke, S.B., Patel, G.B., Pavlis, N.K., Williamson, R.G., Rapp, R.H., Biancle, R. and Nouel, F., 1994b. Gravity model development for TOPEX/Poseidon: Joint gravity models 1 and 2. Journal of Geophysical Research [99(C12)], 24421-24447.

53. Olliver, J.G. 1979. Geoidal studies of Great Britain and Ireland. D.Phil thesis, Oxford University, $196 \mathrm{pp}$.

54. Olliver, J.G., 1980. The gravimetric geoid of Great Britain and Ireland. Geophysical Journal of the Royal Astronomical Society [63], 253-270.

55. Olliver, J.G., 1981. Satellite-derived geoids for Great Britain and Ireland. Survey Review [26], 161179.

56. Olliver, J.G., 1992. Space-derived geoid maps of Great Britain. Survey Review [31], 310-320.

57. Rapp, R.H., 1982, A FORTRAN program for the computation of gravimetric quantities from highdegree spherical harmonic expansions. Report 334, Department of Geodetic Science and Surveying, Ohio State University, Columbus, USA.

58. Rapp, R.H., 1997a. Use of potential coefficient models for geoid undulation determinations using a spherical harmonic representation of the height anomaly/geoid undulation difference, Journal of Geodesy [71], 282-289.

59. Rapp, R.H., 1997b. Past and future developments in geopotential modelling. In Geodesy on the Move: Gravity, Geoids, Geodynamics, and Antarctica (eds. Forsberg, R., Feissl, M. and Dietrich, R.), Springer, Berlin, 58-78.

60. Rapp, R.H. and Cruz, J.Y., 1986. Spherical harmonic expansions of the Earth's gravitational potential to degree 360 using 30' mean anomalies. Report 376, Department of Geodetic Science and Surveying, Ohio State University, Columbus, USA.

61. Rapp, R.H. and Pavlis, N.K., 1990. The development and analysis of geopotential coefficient models to spherical harmonic degree 360. Journal of Geophysical Research [95(B13)], 2185521911. 
62. Rapp, R.H., Wang, Y.M. and Pavlis, N.K., 1991. The Ohio State 1991 geopotential and sea surface topography harmonic coefficient models. Report 410, Department of Geodetic Science and Surveying, Ohio State University, Columbus.

63. Reigber, C. 1989. Gravity field recovery from satellite tracking data. Lecture notes in Earth Sciences 25: Theory of satellite geodesy and gravity field determination, Springer, Berlin, 197-234.

64. Reigber, C., Schwintzer, P., Barth, W., Massmann, F.H., Raimondo, J.C., Bode, A., Li, H., Balmino, G., Biancale, R., Moynot, B., Lemoine, J.M., Marty, J.C., Barlier, F. and Boudon, Y., 1993. GRIM4-C1, C2P: combination solutions of the Earth's gravity field. Surveys in Geophysics [14], 381-393.

65. Robbins, A.R., 1963. A geoid section in Great Britain. Survey Review [128], 69-75 and [129], 121132.

66. Schwintzer, P., Reigber, C., Bode, A., Chen, Z., Massman, F-H., Raimondo, J.C., Lemoine, J.M., Balmino, G., Biancale, R., Moynot, B., Marty, J.C., Barlier, F. and Boudon, Y., 1991. A new Earth gravity model in support of ERS-1 and SPOT-2: GRIM4-S1/C1, DGFI/GRGS, Munich/Tolouse.

67. Schwintzer P., Reigber, C., Barth, W., Massmann, F.H., Raimondo, J.C., Gerstl, M., Bode, A., Li, H., Biancale, R., Balmino, G., Moynot, B., Lemoine, J.M., Marty, J.C., Barlier, F., Boudon, Y.; 1992. GRIM4 Globale Erdschwerefeldmodelle, Zeitschrift für Vermessungswesen, [117], 227-247.

68. Schwintzer, P., Reigber, C., Bode, A., Chen, Z., Massman, F-H., Raimondo, J.C., Lemoine, J.M., Balmino, G., Biancale, R., Moynot, B., Marty, J.C., Barlier, F. and Boudon, Y., 1993. Improvement of GRIM4 Earth gravity models using Geosat altimeter and SPOT-2 and ERS-1 tracking data, In Geodesy and Physics of the Earth (eds Montag, H. and Reigber, C.), Springer, Berlin, 75-78.

69. Schwintzer, P., Reigber, C., Bode, A., Kang, Z., Zhu, S.Y., Massmann, F.H., Raimondo, J.C., Biancale, R., Balmino, G., Lemoine, J.M., Moynot, B., Marty, J.C., Barlier, F. and Boudon, Y., 1997. Long-wavelength global gravity field models: GRIM4-S4, GRIM4-C4, Journal of Geodesy [71(4)], 189-208.

70. Shum, C.K., Tapley, B.D., Yuan, D.N., Ries, J.C. and Schutz, B.E., 1990. An improved model for the Earth's gravity field. In Gravity, Gradiometry and Gravimetry (eds Rummel, R. and Hipkin, R.G.), Springer, Berlin, 97-108.

71. Smith, D.A. and Milbert, D.G., 1999. The GEOID96 high-resolution geoid height model for the United States, Journal of Geodesy [73(5)], 219-236.

72. Stewart, M.P. and Hipkin, R.G. 1989. A high-resolution, high-precision geoid for the British Isles. In Sea Surface Topography and the Geoid (eds Sünkel, H. and Baker, I.), Springer, Berlin, 39-46.

73. Stewart, M.P. 1990. Computation of a gravimetric geoid for Great Britain: an assessment of Fourier and classical techniques. PhD thesis, Edinburgh University. $155 \mathrm{pp}$.

74. Stewart, M.P., Featherstone, W.E., Kirby, J.F. and Dumville, M., 1998. A comparison of GEOSAT and gravimetric geoid profiles in the western North Sea, Marine Geodesy [21(4)], 319-330.

75. Tapley, B.D., Shum, C.K., Yuan, D.N., Ries, J.C. Eanes, R.J., Watkins, M.M., Schutz, B.E., 1991. The University of Texas Earth gravity field model. Presented to the XX General Assembly of the International Union of Geodesy and Geophysics, Vienna.

76. Tapley, B.D., Watkins, M.M., Ries, J.C., Davis, G.W., Eanes, R.J., Poole, S.R., Rim, H.J., Schutz, B.E., Shum, C.K., Nerem, R.S., Lerch, F.J., Marshall, J.A., Klosko, S.M., Pavlis, N.K. and Williamson, R.G., 1996. The joint gravity model 3. Journal of Geophysical Research [101(B12)], 28029-28049.

77. Tapley, B.D., Shum, C.K., Ries, J.C., Poole, S.R., Abusali, P.A.M., Bettadpur, S.V., Eanes, R.J., Kim, M.C., Rim, H.J., and Schutz, B.E., 1997. The TEG-3 geopotential model. In Gravity, Geoid and Marine Geodesy (eds Segawa, J., Fujimoto, H. and Okubo, S.) Springer, Berlin, 453-460.

78. Thompson, K., 1980. An analysis of British monthly mean sea-level. Geophysical Journal of the Royal Astronomical Society [63]: 57-73.

79. Torge, W. and Denker, H., 1998. The European geoid - development over more than 100 years and present status. Proc. Second Continental Workshop on the Geoid in Europe (eds. Vermeer M and Adam, J.) Budapest, March, 47-52. 
80. Torge, W., Weber, G. and Wenzel, H.-G., 1982. Computation of a high resolution European geoid (EGG1). Proc. Second International Symposium on the Geoid in Europe and Mediterranean Area, Rome, 437-460.

81. Torge, W. Weber, G. and Wenzel, H.-G. 1984. High-resolution gravimetric geoid heights and gravimetric vertical deflections of Europe including marine areas. Marine Geophysical Researches [7], 149-175.

82. Vanicek, P. and Featherstone, W.E., 1998. Performance of three types of Stokes's kernel in the combined solution for the geoid, Journal of Geodesy [72], 684-697.

83. Wenzel, H-G., 1998a. Ultra-high degree geopotential model GPM3E97A to degree 1800 tailored to Europe. Proc. Second Continental Workshop on the Geoid in Europe (eds. Vermeer M and Adam, J.) Budapest, Hungary, March, 71-80.

84. Wenzel, H.G., 1998b. Ultra-high degree geopotential models GPM98A, B, and C to degree 1800. Proceedings of the joint meeting of the International Gravity Commission and International Geoid Commission, September 7-12, Trieste, Italy.

85. Wichiencharoen, C., 1982. The indirect effects on the computation of geoidal undulations, Report 336, Department of Geodetic Science and Surveying, Ohio State University, Columbus, USA. 